\title{
Study on Tie Ling city tourism development strategy
}

\author{
Liben Song \\ School of Ai En International, Dalian Jiao Tong University, Dalian 116021, China \\ benjamin1717@163.com
}

Keywords: Tie Ling city, tourism industry, tourism development strategy, SWOT

\begin{abstract}
This paper makes use of the method of SWOT , objectively analyze Ti Ling city tourism development ,the strengths ,weaknesses, opportunities and threats. On the base of this analysis method put forward to the corresponding tourism development strategies.
\end{abstract}

\section{Introduction}

SWOT analysis is an important tool of positioning strategy for an economic body, it can clearly knows the characteristics and the status of the research object and grasp the differences of regional environment and the relations with other similar objects, so that the results of the study based on a certain regional environment and the connection object.This paper uses SWOT analysis of Tie Ling city tourism development, trying to clear the advantage of Tie Ling city tourism development Strengths, Weaknesses and Opportunitiesand challenges, in order to formulate relevant development strategy to enhance the level of Tie Ling city tourism development depth and tourism product competition strength.

Table1: Model of SWOT analysis

\begin{tabular}{|c|c|c|}
\hline & Strengths & Weaknesses \\
\hline Opportunities & $\begin{array}{c}\text { Opportunities-strengths } \\
\text { strategies(OS) }\end{array}$ & $\begin{array}{c}\text { Opportunities-weaknesses } \\
\text { strategies(OW) }\end{array}$ \\
Threats & $\begin{array}{c}\text { Threats-strengths } \\
\text { Strategies(TS) }\end{array}$ & $\begin{array}{c}\text { Threats-weaknesses } \\
\text { strategies(TW) }\end{array}$ \\
\hline
\end{tabular}

\section{The present situation of tourism development}

With the development of Liao Ning province tourism economy, Tie Ling city shows a tendency of the rapid development of tourism industry. In 2014,a total of reception of domestic tourists is 19,495 million, with an increase of $17.4 \%$ over the previous year. Domestic tourism income was 17.17 billion yuan, with an increase of $17.3 \%$ over the previous year.It had received 34000 Inbound tourists, with an increase of $1.3 \%$ over the previous year.Realized Tourist foreign exchange income of \$27.177 million, an increase of $1.9 \%$ over the previous year.Due to the cardinal number of $t$ tourists reception is small, with the formation and developmentas the city leisure culture tourism center, land and humor culture center, Song-Jin dynastycultural tourist center and the royal deer forest resort and so on four big formation of theme tourism center, it will show the trend of rapid growth in tourism customers market.

Results have been obtained at the same time, the problems of the development with tourism industry is also prominent, this paper will shed light on the link in the SWOT analysis.

\section{SWOT analysis}

\section{Strengths analysis}

\section{1) Tourism resources}

According to the tourism bureau for the division of tourism resource categories, Tie Ling city has seven main types, 30 basic types, nearly 60 monomer tourist resources, so Tie Ling is a tourist area with abundant resources in diverse. 


\section{2) Superior location and good accessibility}

Tie Ling locates in the center of the northeast of Asia and also in the center ofLiao Ning urban city agglomeration, an important channel for Jilin provinceand Hei Longjiang province going to other districts and sea ports.Tie Ling city is only45 kilometers from the center of Shenyang, with Jingha highway across the city and connected tothe large and medium-sized cities. So Tie Ling has laid a good traffic conditions for its tourism development.

3) learn from the advanced experience and disadvantages

Tourism industry of Tie Ling citystarted relatively later than other cities. In the process of development, it can draw lessons from success and failure experiences in other areas, such as management system and new methods etc.

\section{Weaknesses analysis}

1) The overall tourism development started late, tourism resource development degree needs to improve

Current tourism resource development still stays in the primary stage, the study of tourism products lacks of depth, breadth, and integrity.Overall, the development of tourism products still stays in the sightseeing level, it is lacking of new growth point, ignoring the tourists demand for participation, entertaining and informative tourist product.

\section{2) Regional tourism image is not clear and unique}

Although Tie Ling hashistorical and cultural resourcesrepresented by the"four card" (culture of Red Mansion, art of Chinese short talk show, sports champions city, coal energy city) and the name of "large city - Tie Ling" also be marked in domestic, but the tourism slogan is too miscellaneous, and not refined, feeling giving a person is the overall image of regional tourism more fuzzy, so it directly affects the city tourism publicity.

3) Lack of modern tourism function, need to improve the whole quality of tourism enterprises

The travel agency industry is small, weak, scattered distribution, this restrict the development of tourism.High-class reception facilities is relatively small, and the reception level needs to be improved.The imperfection of hardware hinders it to develop high quality tourist market.

4) Lack of funds and talents

Tourism development and promotion, shortage of funds. Because of the limitation of economic capacity, lead to the introduction of capital to develop tourism channel is not smooth in the process of tourism development and construction, which hindered the further development of local tourism.

Lack of professional tourism management talents. Quantity of tourism human resources , especially the cultivation of high-level personnel needs to be strengthened.

\section{Opportunities analysis}

1) Revitalization of northeast old industrial base

Liao Ning province is entering the ranks of the strong economic development city, it makes a very big space for the development of tourism industry, and great changes have taken place in tourism development environment, for the development of Liao Ning tourism provides a good opportunity.

\section{2) Large spaceregional tourism cooperation development}

Liao Ning province made a decision that build economic zone development strategy with the core city of Shenyang and the vice cities of Anshan, Fushun, Ben Xi, Liao Yang, Tie Ling, Tie Ling as the back garden of Shenyang economy in policy. As the light rail and bus system put into use between Shenyang and Tie Ling, enlarge the tourism source markets for Tie Ling .

\section{3) Opportunity of being awarded China's excellent tourism city}

Tie Ling city was officially awarded the "China excellent tourist city" by the national tourism administration approval .The victory of assessment phase , the tourism development of Tie Ling raised a new level, will be conducive to Tie Ling city tourism development work for next step. 


\section{Threats analysis}

\section{1) Competition with the surrounding cities}

Surrounding cities such as Shenyang, Manchu of Fushun autonomous county of Qingyuan earlier to develop tourism, and has formed a certain scale and the effect of a new round of the development of the tourism boom will no doubt bring new challenges to the development of Tie Ling tourism.

2) Effect of "covered" image

Shenyang is in the south of Tie Ling, Manchu autonomous county of Fushun radically in the east of Tie Ling, famous tourist scenic spot of Jilin province is in the north of Tie Ling and it is close to Inner Mongolia which owns full of Folk customs. So it is difficult to attract tourists from remote market to Tie Ling.

\section{Tourism development strategy}

Tourism development SWOT analysis shows that the advantage of Tie Ling city tourism is more outstanding, opportunity is rare, but it is clearly at the same time, external environmental threat is obvious.Therefore Tie Ling city tourism development should be taken to rely on the internal advantage, using the external opportunities and constantly enhance their competitive strength, to foster a competitive development strategy of tourism brand, attaches great importance to the joint with the central Liao Ning province urban agglomeration.Can adopt strategies are:

\section{Government leading, the whole people participating strategy}

Government leading, the participative strategy is adopted by many countries and regions in the world today, its core is to stick to the government on tourism economy plays a leading role at the same time, pay attention to the role of market mechanism, and give full use to the strength of all citizens, to achieve the rational allocation of market resources and optimize the combination.The government in the development of tourism industry, plays a leading role, for the development of tourism industry and create a good environment for the whole tourism.

\section{Multi-channel capital financing strategy}

Deep level development of tourism industrymust take strong capital. At present, Tie Ling should establish market-oriented operation of the investment mechanism, through various channels to raise funds.Therefore, it needs to deepen the system reform, actively create a good investment environment and capital operation method, draw lessons from other industry in the aspect of capital financing, so vigorously attract foreign capital, private capital and private capital to participate in the development and operation of tourism projects.

\section{Sustainable development strategy}

The core of sustainable development is based on economic benefit, social benefit and environmental ecological benefits. The government must according to the transportation, land, water and other resources bear ability, make the development of tourism planning, makethe growth of the tourism industry to maintain a moderatescale.Don't develop blindly the industry and repeatedconstruction. At the time of planning, government should stick to protect first, followed by the principle of development and utilization.

\section{Summary}

In this paper, according to the basic theory of urban tourism planning, together with the present situation of the tourismdevelopment of Tie Ling city, using the SWOT analysis method studied in all aspects of Tie Ling city tourism development, put forward the corresponding tourism development strategies.

\section{References}

[1] Briggs S. Successful Tourism Marketing: A Practical Handbook[J]. Kogan Page Limited, 1997, 15(3): 167-212 
[2] Gang Song. Tourism marketing[M].BeijingEconomic and trade University press, [M], 2009

[3] Bihu Wu. Regiona tourism development and management[M].Beijingscience press, 2009

[4] Cai Chen,Rui Ni,Mingming Fei.Study on the strategy of Fu Xin city tourism management[J]. Academic Journal of Liao Ning Normal University(social science ),2007(9) 